\title{
CARACTERIZAÇÃO FÍSICO-QUÍMICA E REOLÓGICA DE FARINHAS MISTAS DE TRIGO E LINHAÇA
}

\author{
JOÃO TOMAZ DA SILVA BORGES* \\ MÔNICA RIBEIRO PIROZI** \\ JOSÉ BENÍCIO PAES CHAVES*** \\ ROGÉRIO GERMANI**** \\ CLÁUDIA DENISE DE PAULA****
}

\begin{abstract}
O objetivo deste trabalho foi determinar o efeito da mistura de farinha integral de linhaça e farinha de trigo especial nas características físico-químicas e reológicas da massa obtida para utilização em produtos de panificação. Farinhas mistas foram preparadas com a substituição parcial da farinha de trigo pela farinha integral de linhaça nas proporções de 100:00, 95:5, 90:10, 85:15, 80:20 e 75:25. A incorporação da farinha integral de linhaça afetou a distribuição granulométrica, produzindo farinhas mistas com granulometria mais grosseira e de cor mais escura, devido principalmente à presença de periderme da semente de linhaça na mistura. Embora tenha favorecido maiores percentuais de lipídios, fibra bruta, cinzas e proteínas, houve diminuição de qualidade tecnológica das farinhas mistas com o aumento nos níveis de substituição de farinha de trigo pela farinha integral de linhaça na mistura. Esse comportamento foi observado principalmente pela redução de extensibilidade, estabilidade, tempo de desenvolvimento da massa e aumento do índice de tolerância à mistura. Essa interferência negativa deve-se, principalmente, ao efeito das fibras nas propriedades tecnológicas da massa, o que poderá ser corrigido pelo uso de aditivos e/ou de ajustes no processamento de modo a promover o desenvolvimento de características desejáveis à produção de pães.
\end{abstract}

PALAVRAS-CHAVE: FARINHA DE TRIGO; FARINHA INTEGRAL DE LINHAÇA; FARINHA MISTA; CARACTERÍSTICAS FÍSICO-QUÍMICAS; CARACTERÍSTICAS REOLÓGICAS.

* Doutor em Ciência e Tecnologia de Alimentos, Professor, Instituto Federal de Ciência e Tecnologia do Espírito Santo, Venda Nova do Imigrante, ES (e-mail: jtsborges@ifes.edu.br).

** Ph.D. em Ciência de Grãos, Professora, Departamento de Tecnologia de Alimentos (DTA), Universidade Federal de Viçosa (UFV), Viçosa, MG (e-mail: mpirozi@ufv.br).

*** Doutor em Ciência de Alimentos, Professor, DTA, UFV, Viçosa, MG (e-mail: jbchaves@ufv.br).

**** Doutor em Ciência de Cereais, Pesquisador, Centro Nacional de Pesquisa de Tecnologia Agroindustrial de Alimentos (EMBRAPA Agroindústria de Alimentos), Rio de Janeiro, RJ (e-mail: germani@ctaa.embrapa.br).

***** Doutora em Ciência e Tecnologia de Alimentos, Professora, Departamento de Ingeniería de Alimentos, Facultad de Ingeniería, Universidad de Córdoba, Colombia (e-mail: cdenise@correo.unicordoba.edu.co). 


\section{INTRODUÇÃo}

Linhaça é o nome dado à semente do linho (Linum usitatissimum L.), planta cultivada comercialmenteem diversos países com destaque para o Canadá, que responde por aproximadamente $40 \%$ da produção mundial (MANDARINO, ROESSING e BENASSI, 2005; MACIEL, PONTES e RODRIGUES, 2008). A maior parte do cultivo comercial não é destinada para alimentação, sendo a demanda mundial dominada pelos usos industriais do óleo de linhaça, principalmente em pintura (COSKUNER e KARABABA, 2007).

Apesar da importância relativamente pequena como alimento, a linhaça é conhecida por seu alto conteúdo em fibras solúveis mucilaginosas, com implicações positivas sobre quadros de hiperglicemia e hipercolesterolemia em humanos. A demanda crescente por proteínas vegetais vem intensificando o estudo desse grão como fonte de alimento para o homem (LI-CHAN e MA, 2002). Em sua composição destacam-se cerca de $30 \%$ a $40 \%$ de lipídios, $20 \%$ a $25 \%$ de proteína e $20 \%$ a $28 \%$ de fibra alimentar total, além das vitaminas A, B, D, E e minerais (potássio, fósforo, magnésio, cálcio e outros) (OOMAH e MAZZA, 1993; OOMAH, 2001).

Pode-se dizer que a fração lipídica da linhaça é rica em ácidos graxos poliinsaturados (73\%), moderada em ácidos graxos monoinsaturados (18\%) e baixa em ácidos graxos saturados (9\%). O ácido linoleico constitui cerca de $16 \%$ do total de ácidos graxos, enquanto o ácido $\alpha$-linolênico representa cerca de $57 \%$, superando qualquer óleo de origem vegetal (RAMCHARITAR et al., 2005). Alguns estudos têm sido desenvolvidos com a aplicação dessa semente em produtos de panificação (RAMCHARITAR et al., 2005; CONFORTI e DAVIS, 2006; KOCA e ANIL, 2007), seja na forma de semente ou ainda pela utilização de seu óleo.

A avaliação das características físico-químicas e reológicas assume vital importância para a indústria de panificação, ajudando a predizer as características de processamento da massa e a qualidade dos produtos finais. Entre as determinações disponíveis para avaliar objetivamente a qualidade tecnológica de farinhas incluem-se as análises das características de mistura (farinógrafo e mixógrafo), de extensão (extensógrafo, alveógrafo e consistógrafo) e número de queda (BRASIL, 2001; QUEJI, SCHEMIN e TRINDADE, 2006; GUTKOSKI et al., 2008).

O objetivo deste trabalho foi determinar o efeito da mistura de farinha integral de linhaça e farinha de trigo especial nas características físico-químicas e reológicas da massa obtida para utilização em produtos de panificação.

\section{MATERIAL E MÉTODOS}

\subsection{MATÉRIAS-PRIMAS E FARINHAS MISTAS DE TRIGO E LINHAÇA}

Foram utilizadas como matérias-primas farinha de trigo especial $(\mathrm{FT})$ e farinha integral de linhaça (FIL), adquiridas no comércio de Viçosa, Minas Gerais. As farinhas mistas foram preparadas em misturadora vertical marca Brasil, modelo 56 RC 6504, com batedor tipo gancho, pela substituição parcial da farinha de trigo pela farinha integral de linhaça nas proporções de 100:00 (FT), 95:5 (F5), 90:10 (F10), 85:15 (F15), 80:20 (F20) e 75:25 (F25). Para cada farinha mista foram preparadas 3 bateladas (repetições) de $5 \mathrm{~kg}$ cada, submetidas à homogeneização por 10 minutos para melhor uniformidade da mistura. As farinhas foram embaladas em sacos plásticos de polietileno com capacidade para $10 \mathrm{~kg}$, identificadas e mantidas sob refrigeração até o momento das análises.

\subsection{ANÁLISE FÍSICA DAS FARINHAS MISTAS DE TRIGO E LINHAÇA}

\subsubsection{Granulometria das farinhas mistas}

A distribuição granulométrica das farinhas mistas foi determinada por meio de equipamento 
Ro-Tap e conjunto de seis peneiras arredondadas, com aberturas de 590, 420, 350, 297, 250 e 210 micrômetros de malha (Método 965-22, AOAC, 1995).

\subsubsection{Cor das farinhas mistas}

A quantificação objetiva de cor ocorreu em colorímetro triestímulo, com leitura direta de reflectância das coordenadas de cromaticidade "L" (luminosidade), "a" (tonalidades de vermelho a verde) e "b" (tonalidades de amarela a azul), empregando-se a escala Hunter-Lab. As amostras de farinhas foram colocadas em cubeta e submetidas à leitura no colorímetro. Nesse sistema de cor, corrigido pela CIELab, os valores $L^{*}$ (luminosidade) variam de zero (preto) e 100 (branco), os valores de $a^{*}$ variam de $-a^{*}$ (verde) até $+a^{*}$ (vermelho) e os valores de $b^{*}$ variam de $-b^{*}$ (azul) até $+b^{*}$ (amarelo) (HUNTERLAB, 1998).

\subsection{ANÁLISES FÍSICO-QUÍMICAS DAS FARINHAS MISTAS DE TRIGO E LINHAÇA}

Analisou-se a composição centesimal das farinhas segundo a metodologia da AOAC, ou seja, umidade (Método 925-10, AOAC 1996), lipídios (Método 920-85, AOAC 1996), proteína (Método 960-52, AOAC 1996), cinzas (Método 923-03, AOAC 1996), fibra bruta (Método 991-43, AOAC 1995) e carboidratos determinado por diferença [100 - (lipídios + proteína bruta + cinzas + fibra bruta)].

\subsection{ANÁLISES REOLÓGICAS DAS FARINHAS MISTAS DE TRIGO E LINHAÇA}

\subsubsection{Farinografia}

Para o teste de farinografia utilizou-se farinógrafo Brabender de acordo com o Método 5421 da AACC (1995). Foram determinados os parâmetros de absorção de água (ABS), estabilidade (EST), tempo de desenvolvimento da massa (TDM) e índice de tolerância à mistura (ITM).

\subsubsection{Extensografia}

Para avaliação das propriedades extensíveis das massas empregou-se extensógrafo Brabender, segundo o Método 54-10 da AACC (1995). Os parâmetros avaliados pelo extensograma foram resistência máxima à extensão (Rmax) e extensibilidade $(E)$.

\subsubsection{Número de queda}

O Número de queda (NQ) foi determinado por meio do aparelho "Falling Number", de acordo com o Método 56-81B da AACC (1995), sendo o resultado expresso em segundos (s).

\subsection{DELINEAMENTO EXPERIMENTAL E ANÁLISE ESTATÍSTICA}

Adotou-se delineamento experimental de misturas com seis formulações de trigo: linhaça nas proporções de 100:0 (FT), 95:05 (F5), 90:10(F10), 85:15 (F15), 80:20 (F20) e 75:25 (F25), em delineamento inteiramente casualizado com 3 repetições, totalizando 18 unidades experimentais. $O$ efeito das misturas de farinha de trigo e farinha integral de linhaça sobre as características físico-químicas e reológicas, quando significativo foi avaliado por meio de análise de regressão.

Para análise dos dados utilizou-se o programa Statistical Analysis System (SAS, 2009) versão 9.1, licenciado para a Universidade Federal de Viçosa, Minas Gerais. 
3 RESULTADOS E DISCUSSÃO

\subsection{GRANULOMETRIA DAS FARINHAS MISTAS DE TRIGO E LINHAÇA}

A granulometria das farinhas mistas encontra-se ilustrada na Tabela 1.

TABELA 1 - DISTRIBUIÇÃO GRANULOMÉTRICA DAS FARINHAS MISTAS DE TRIGO E LINHAÇA

\begin{tabular}{cccccccc}
\hline & \multicolumn{7}{c}{ Retenção de partículas (\%) } \\
\cline { 2 - 8 } Farinhas & $\mathbf{7}$ & \multicolumn{7}{c}{ Abertura de malha (micrômetros) } \\
\cline { 2 - 8 } & $\mathbf{5 9 0}$ & $\mathbf{4 2 0}$ & $\mathbf{3 5 0}$ & $\mathbf{2 9 7}$ & $\mathbf{2 5 0}$ & $\mathbf{2 1 0}$ & $<\mathbf{2 1 0}$ \\
\hline FIL & 60,77 & 11,83 & 11,70 & 7,43 & 3,14 & 2,81 & 2,31 \\
FT & 0 & 0 & 0 & 0,05 & 0,05 & 0,04 & 99,86 \\
\hline F5 & 3,71 & 0,67 & 0,22 & 0,82 & 0,26 & 0,70 & 93,62 \\
F10 & 7,83 & 2,38 & 1,37 & 5,60 & 1,05 & 0,90 & 80,87 \\
F15 & 10,89 & 2,21 & 1,20 & 1,79 & 1,05 & 1,58 & 81,28 \\
F20 & 13,52 & 3,12 & 1,41 & 2,55 & 1,17 & 1,75 & 76,48 \\
F25 & 17,22 & 3,06 & 1,60 & 2,83 & 1,37 & 2,64 & 71,27 \\
\hline
\end{tabular}

FIL = farinha integral de linhaça; FT = farinha de trigo especial.

Percentual acima de $98 \%$ de FT passou pela peneira 250 micrômetros, conforme determina a Portaria n. 354, de 18 de julho de 1996 (ANVISA, 1996), sendo esse reduzido com o aumento de FIL na formulação. Esses resultados encontram-se de acordo com os dados relatados por Gutkoski e Pedó (2000). Com o aumento de farinha integral de linhaça na formulação houve incremento na retenção de partículas na peneira com abertura de 590 micrômetros.

A característica granulométrica da matéria-prima constitui aspecto relevante na panificação, permitindo maior uniformidade do produto elaborado. $O$ tamanho de partícula influencia diretamente a capacidade de absorção de água, o tempo de mistura e as características sensoriais (como aparência, sabor e textura) (BORGES et al., 2003). A influência da granulometria de farinhas nas propriedades de produtos de panificação ainda não foi totalmente elucidada, embora seja aceito que partículas finas e uniformes promovem maior dispersibilidade da farinha na massa. Para Pyler (1988), granulometria extremamente fina da farinha não é sinônimo de qualidade, uma vez que pode prejudicar a estrutura interna de produtos de panificação, tornando-a úmida e gomosa.

\subsection{COR DAS FARINHAS MISTAS}

Observando os dados da Tabela 2 percebe-se que a FIL apresentou coloração mais escura quando comparada a FT, o que pode ser verificado pelos valores de $L^{*}$, $a^{*}$ e $b^{*}$. Desta forma, as farinhas mistas apresentaram-se mais escuras com o aumento nos níveis de substituição de FT por FIL na mistura. Tendência semelhante foi também observada por Shearer e Davies (2005).

Os valores de b* para a FT e FIL foram 9,68 e 14,26, respectivamente, indicando tendência para a cor amarela nas farinhas mistas com incremento dos níveis de FIL na formulação.

A incorporação da periderme à farinha integral é o principal responsável pela coloração e tonalidades escuras das farinhas mistas. De modo geral, as farinhas para panificação devem ser "brancas", porém produtos considerados "integrais" têm coloração naturalmente mais escura (marrom avermelhado) como foi observado nas farinhas mistas neste trabalho. 
TABELA 2 - COORDENADAS DE CROMATICIDADE L* $\mathbf{a}^{*} \mathbf{b}^{*}$ DA FARINHA INTEGRAL DE LINHAÇA (FIL), FARINHA DE TRIGO (FT) E FARINHAS MISTAS

\begin{tabular}{cccc}
\hline \multirow{2}{*}{ Farinhas } & \multicolumn{3}{c}{ Coordenadas de cromaticidade } \\
\cline { 2 - 4 } & $\mathbf{L}^{*}$ & $\mathbf{a}^{*}$ & $\mathbf{b}^{*}$ \\
\hline FIL & $53,51 \pm 0,21$ & $4,34 \pm 0,12$ & $14,26 \pm 0,54$ \\
FT & $96,64 \pm 0,02$ & $0,46 \pm 0,01$ & $9,68 \pm 0,05$ \\
\hline F5 & $91,55 \pm 0,12$ & $0,37 \pm 0,01$ & $9,57 \pm 0,11$ \\
F10 & $90,61 \pm 0,16$ & $0,37 \pm 0,01$ & $9,46 \pm 0,03$ \\
F15 & $88,88 \pm 0,11$ & $0,43 \pm 0,04$ & $9,87 \pm 0,02$ \\
F20 & $85,32 \pm 0,48$ & $0,51 \pm 0,09$ & $10,22 \pm 0,43$ \\
F25 & $84,51 \pm 0,24$ & $0,65 \pm 0,02$ & $10,16 \pm 0,23$ \\
\hline
\end{tabular}

FIL = Farinha integral de linhaça; FT = farinha de trigo especial.

\subsection{ANÁLISES FÍSICO-QUÍMICAS DAS FARINHAS MISTAS DE TRIGO E LINHAÇA}

A farinha de trigo (F0) e as misturas $\mathrm{F} 5, \mathrm{~F} 10, \mathrm{~F} 15, \mathrm{~F} 20$ e F25 foram avaliadas quanto ao teor de umidade, apresentando, respectivamente, 13,56\%; 12,86\%; 12,67\%; 12,07\%; $11,75 \%$ e $11,65 \%$. Esses resultados encontram-se de acordo com aqueles obtidos por Maciel, Pontes e Rodrigues (2008) em farinhas mistas de trigo e linhaça, sendo considerados seguros pela legislação brasileira que estabelece o máximo de $15 \%$ de umidade para esse produto (BRASIL, 2005).

A adição de FIL promoveu incremento nos teores lipídicos das farinhas mistas, com diferença significativa a $5 \%$ de probabilidade. Dentre os modelos testados, o linear foi o que melhor explicou a variação nos teores lipídicos nas farinhas mistas, com coeficiente de determinação de 98,68\%. Na Figura $1 \mathrm{~A}$ verifica-se a variação de lipídios em função da presença de FIL nas farinhas mistas.
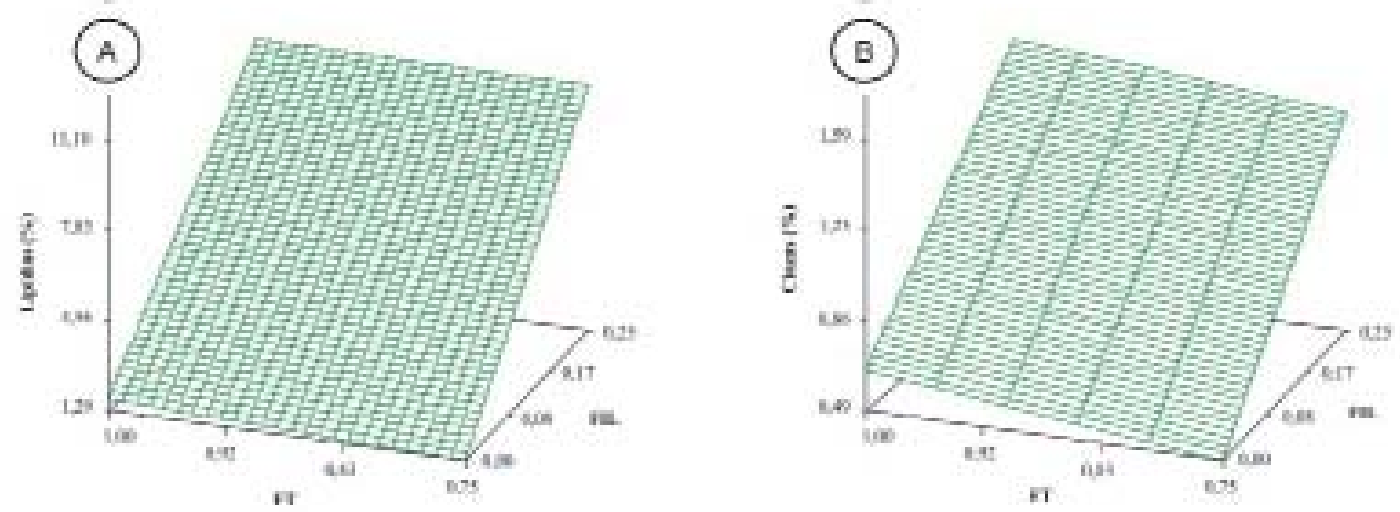
(A) Lipidios $(\%)=1,73 \mathrm{FT}+37,50 \mathrm{FE}$
$R^{2}=0,99$
(B) Cinzass $(\%)=0,66 \mathrm{FT}+3,74 \mathrm{FIL}$
$R^{3}=0,97$

\section{FIGURA 1 - GRÁFICO DE SUPERFÍCIE DE RESPOSTA PARA A VARIAÇÃO DE LIPÍDIOS E CINZAS DAS FARINHAS MISTAS DE TRIGO E LINHAÇA}

O teor de lipídios nas farinhas mistas variou de 1,78\% (FT) a 10,92\% (F25), sendo o valor 
encontrado para FT superior ao verificado por Lima (2007).

De modo geral, os efeitos dos lipídios em panificação incluem a modificação da estrutura do glúten no estágio de mistura, a polimerização das proteínas por meio dos processos que envolvem a oxidação lipídica, melhor retenção de gás pelo selamento das células, além de ação lubrificante e retardamento no envelhecimento do pão. Os lipídios naturais da farinha de trigo compreendem, aproximadamente, $2 \%$ de seu peso total, podendo ser classificados como livres (não polares) e ligados (polares) (LI, DOBRASZCZYK e WILDE, 2004; MCCANN et al., 2009; FINNIE et al., 2010).

Os lipídios polares associam-se à gliadina, exercendo efeito positivo sobre as propriedades reológicas e auxiliando o desenvolvimento da massa pela habilidade que apresentam de se ligarem à proteína e ao amido. Também reforçam a parede das células de gás, aumentando o volume do produto final. Os lipídios não polares encontram-se na superfície de partículas de amido ou dispersos na massa sob a forma de pequenas gotículas (KELLER, ORSEL e HAMER, 1997; GUNNING et al., 1999; LI, DOBRASZCZYK e WILDE, 2004).

O estudo de Oomah, Mazza e Przybylski (1996) a respeito da composição lipídica de semente de linhaça, utilizando diferentes solventes, comprovou a predominância de lipídios polares. Dessa forma, o aumento de lipídios obtidos nas farinhas mistas pode ser favorável ao processamento de pão de sal. Considerando o efeito dos lipídios da farinha nas propriedades do glúten, esse incremento pode ser interessante sob o ponto de vista tecnológico por agir positivamente na estrutura proteica da massa, além de favorecer maior retenção de gases, contribuindo para maior volume e maciez dos pães.

A farinha de linhaça contém alta concentração de ácidos graxos poliinsaturados, representando problema potencial para a sua estabilidade, bem como das diferentes farinhas mistas estudadas pela susceptibilidade a reações de rancificação durante o armazenamento. Esses efeitos podem ser eliminados pela ação do calor empregado no forneamento sobre as enzimas catalisadoras dessas reações (peroxidases e lipases), ou minimizados por substâncias antioxidantes (como tocoferol, vitamina $\mathrm{C}$ e lignanos) naturalmente presentes nessa matéria-prima, associadas à embalagem que impeça a permeação de agentes potencializadores como oxigênio e luz, dentre outros (FREITAS e MORRETTI, 2006; MACIEL, PONTES e RODRIGUES, 2008; MOURA, 2008; MORAES et al., 2010).

Na Figura 1B é apresentado gráfico de superfície de resposta para cinzas nas farinhas mistas de trigo e linhaça. Houve incremento significativo no teor de cinzas com o aumento de FIL e FT, sendo $96,72 \%$ das variações ocorridas explicadas pelo efeito linear da regressão.

Com o aumento nos níveis de adição de FIL obteve-se incremento no conteúdo de cinzas em comparação a FT $(0,45 \%)$, chegando a $62,25 \%$ na maior concentração (F25). Hussain et al. (2006) observaram essa elevação do teor de cinzas, quando adicionaram farinha de linhaça em "cookies". Essas diferenças são atribuídas aos minerais presentes na farinha de linhaça. O teor de cinzas obtido na farinha de linhaça no presente estudo foi de 3,52\%, próximo ao valor encontrado por Moura (2008). O conteúdo de cinzas da farinha de trigo é considerado importante medida de qualidade. Seu teor por si só não está relacionado com a qualidade final do produto, mas fornece indicações sobre o grau de extração (GUTKOSKI, NODARI e JACOBSEN NETO, 2003). Na legislação brasileira, o teor de cinzas é empregado para classificar a farinha de uso doméstico entre especial, comum e integral, sendo que o conteúdo obtido para as farinhas mistas no presente trabalho foi característico de farinhas integrais.

O teor de fibra bruta nas farinhas mistas aumentou $(p<0,05)$ com o incremento de farinha de linhaça na formulação. Conforme a Figura $2 \mathrm{~A}$, o efeito linear explicou $96,49 \%$ das variações ocorridas nessa variável. Resultados semelhantes foram obtidos por Bombo (2006) em farinhas mistas de milho e linhaça nas proporções de 70:30. A linhaça tem sido amplamente utilizada como fonte de componentes bioativos no campo dos alimentos funcionais. Também representa uma das mais ricas fontes de ácido graxo a-linolênico, fibra alimentar e lignanas (MEAGHER e BEECHER, 2000; ZHANG et al., 2009). 


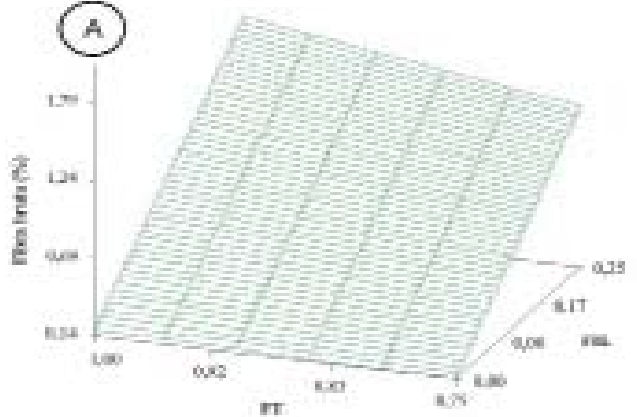

(A) Fibra buta $(\%)=0,29 \mathrm{FT}+6,22 \mathrm{Fil}$.

(B) Proteina $(\%)=14,24 \mathrm{FT}-560,21 \mathrm{FIL}+1496,50 \mathrm{FT} * \mathrm{FIL}-978,37 \mathrm{FT} * \mathrm{FT} * \mathrm{FIL}$

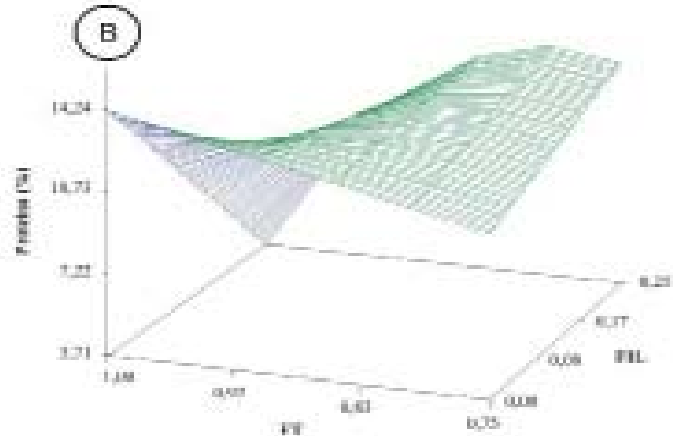

$R^{2}=0,95$

\section{FIGURA 2 - GRÁFICO DE SUPERFÍCIE DE RESPOSTA PARA A VARIAÇÃO DE FIBRA BRUTA E PROTEÍNA DAS FARINHAS MISTAS DE TRIGO E LINHAÇA}

Altos teores de fibra foram verificados por Justo et al. (2007) em pães provenientes de farinhas mistas: trigo, linhaça e soja nas proporções de 85:10:05. Tais autores atribuíram esse resultado ao conteúdo de fibra alimentar presente na linhaça $(22,60 \%)$.

A utilização de ingredientes integrais, ricos em fibras, favorece a obtenção de produtos de panificação de coloração mais escura, textura mais firme e de reduzido volume, limitando o consumo e a aplicação de inúmeras matérias-primas em diferentes formulações alimentícias. O aumento no teor de fibra nessas farinhas mistas poderá ser prejudicial à panificação pela formação de barreira física na matriz do glúten, agindo como pontos de fraqueza ou "stress" (FONSECA FILHO et al. 1997; WANG, ROSELL e BARBER, 2002) e prejudicando a expansão da massa durante a fermentação.

Com o aumento da demanda por alimentos naturais, as indústrias estão pesquisando novos métodos para obtenção de melhorias de características como maciez, textura e maior durabilidade dos pães, geralmente obtidas com a utilização de aditivos químicos. Nesse contexto, coadjuvantes tecnológicos "naturais" que não foram produzidos por síntese química (como as enzimas) vêm sendo cada vez mais utilizados (HAROS, ROSELL e BENEDITO, 2002; NÉRON et al., 2004).

As enzimas são empregadas na elaboração de diversos produtos e ingredientes alimentícios. Em panificação são utilizadas como componentes de melhoradores ou condicionadores de massas, atuando nas moléculas do amido e outros carboidratos ou proteínas, aumentando o volume do pão e melhorando a estrutura do miolo (POUTANEN, 1997; HASAN, SHAH e HAMEED, 2006).

Além das amilases, vêm sendo introduzidas novas enzimas na tecnologia de panificação, dentre as quais destacam-se hemicelulases, glicose-oxidases, xilanases, lipases e proteases (VAN DER MAAREL et al., 2002; LEÓN, DURÁN e BARBER, 2002; GIMÉNEZ et al., 2007).

A utilização de farinha integral de linhaça interferiu no teor proteico das farinhas mistas, com diferença significativa a 5\% de probabilidade. Na Figura 2B são apresentados os resultados em função da porcentagem de substituição de farinha de trigo pela farinha integral de linhaça. O modelo cúbico especial foi o que melhor explicou a variação desse macro-nutriente nas farinhas mistas, com $\mathrm{R}^{2}$ de $95,03 \%$.

Pode-se perceber redução no teor de proteína com a incorporação de FIL à mistura, cujos valores aumentaram com o incremento nos níveis de substituição da farinha de trigo (Figura 2B). 
Sob o ponto de vista tecnológico isto pode ser indesejável, uma vez que essas proteínas não são formadoras de glúten (WU, HUFF e HSIEHI, 2007), favorecendo sua diluição e enfraquecimento, além de comprometer propriedades importantes para a produção de pães. O uso de condicionadores de massa (LOPES et al., 2007; ANVISA, 1999), como ácido ascórbico por exemplo, pode minimizar os efeitos prejudiciais dessas proteínas sobre a massa por atuarem diretamente sobre a estrutura do glúten, reforçando-a. Ademais, afetam positivamente a reologia da massa, diminuindo sua extensibilidade e aumentando a resistência à extensão e a capacidade de retenção de gases, resultando em pães com maior volume.

Os teores de proteína obtidos encontram-se de acordo com a sugestão de Guarienti (1996) para fabricação de pão francês $(10,50 \%$ a $13,00 \%)$ e pão de forma (11,50\% a $14,50 \%)$. Segundo Felício et al. (2001), esse parâmetro apenas complementa os demais a serem analisados, pois a qualidade de panificação está, também, relacionada à qualidade das proteínas presentes na farinha.

A adição de FIL reduziu os teores de carboidratos nas farinhas mistas $(p<0.05)$. O modelo cúbico especial foi o que melhor explicou a variação desse componente nas farinhas mistas em função da substituição da FT pela FIL. O $\mathrm{R}^{2}$ para esse modelo indicou que a regressão explicou $99,93 \%$ da variação dos dados observados. Incremento nos teores de FIL na formulação reduziu os teores de carboidratos totais nas farinhas mistas de $83,16 \%$ (FT) para $73,24 \%$ (F25). Comportamento semelhante foi verificado por Maciel, Pontes e Rodrigues (2008) ao substituírem 5\% a 15\% de farinha de trigo por farinha integral de linhaça.

A redução nos teores de carboidratos, associada à alta concentração de fibras e proteínas não formadoras de glúten relacionam-se a produtos de panificação com características indesejáveis de volume, cor e textura. $\mathrm{O}$ amido, proveniente da farinha de trigo, é considerado carboidrato de suma importância por contribuir para a formação da estrutura do pão no cozimento, da consistência e da textura do miolo, favorecendo o volume e a cor (QUEJI, SCHEMIN e TRINDADE, 2006). Além disso, é substrato para as enzimas diastásicas ( $\alpha$ e $\beta$ amilases), que desdobram o grânulo em dextrina e maltose.

\subsection{ANÁLISES REOLÓGICAS DAS FARINHAS MISTAS DE TRIGO E LINHAÇA}

\subsubsection{Absorção de água e propriedades de mistura}

A incorporação de farinha de linhaça aumentou $(p<0,05)$ os teores de absorção de água nas farinhas mistas, sendo o modelo quadrático aquele que melhor explicou os resultados obtidos em função da substituição da FT pela FIL. O $\mathrm{R}^{2}$ para esse modelo indicou que a regressão explicou $99,27 \%$ da variação dos dados observados (Figura $3 A$ ).

De acordo com Basman e Koksel (1999), Wang, Rosell e Barber (2002), Hu et al. (2009), Seyer e Gelinas (2009) ao se utilizar a farinha de trigo associada às matérias-primas ricas em fibra é de se esperar que ocorra aumento na capacidade de absorção de água pela massa, seguida de diversas modificações nas propriedades reológicas da mistura.

Em FT puras, a absorção de água é influenciada por fatores como o teor e a qualidade da proteína e do amido. De modo geral, maior absorção favorece o ponto de vista econômico, pois seu rendimento em massa será maior. Neste trabalho, o aumento da absorção de água se deve à elevação da quantidade de fibra bruta presente na farinha mista. Isto foi provavelmente causado pelo grande número de grupos hidroxilas existentes na estrutura das fibras, o que permite maior número de interações e mais água por meio de ligações de hidrogênio (ROSELL, ROJAS e BARBER, 2001; COSKUNER e KARABABA, 2007). Resultado semelhante foi observado por Tedrus et al. (2001) ao adicionarem farinha de aveia à de trigo e por Perez e Germani (2004) que usaram farinha mista de trigo e berinjela. 

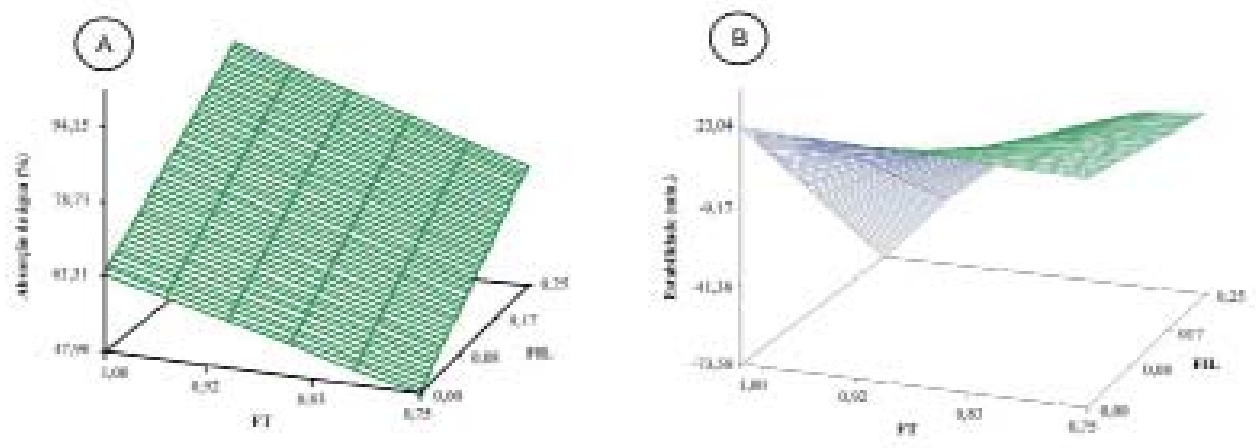

(A) Absorgao de agua (\%) $=63,85 \mathrm{FT}+47,85 \mathrm{FIL}+73,31 \mathrm{FT}^{2} \mathrm{FIL}$

$R^{2}=0,99$

(B) EST (min) $=23,04 \mathrm{FT}-2985,31 \mathrm{FIL}+7852,15 \mathrm{FT}^{*} \mathrm{FIL}-5253,33 \mathrm{FT}{ }^{*} \mathrm{FT}{ }^{\circ} \mathrm{FIL} \quad \mathrm{R}^{2}=0,97$
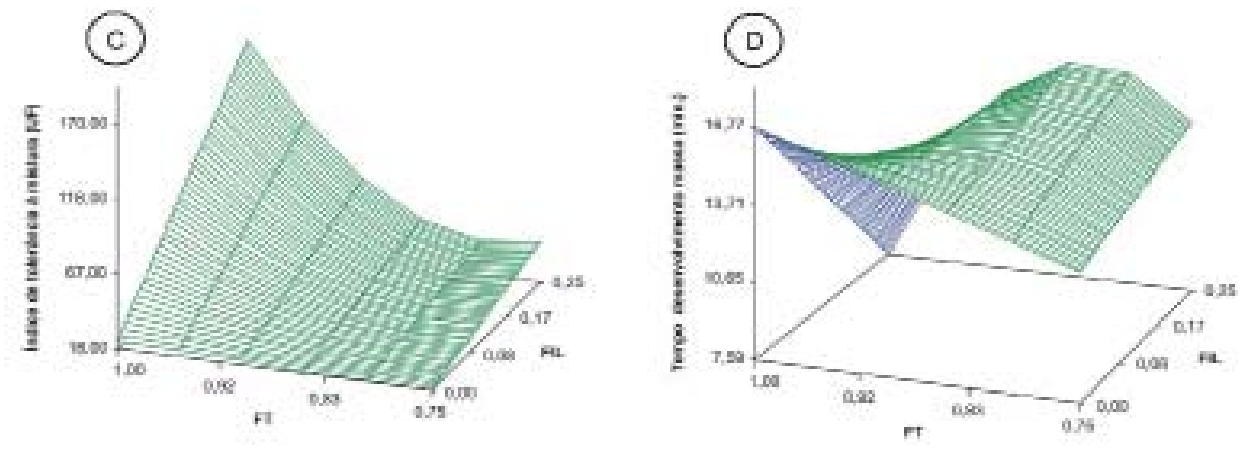

(C) $\mathrm{TM}$ (UF) $=21,56 \mathrm{FT}+7377,83 \mathrm{FIL}-18382.00 \mathrm{FT} * \mathrm{FIL}+11596,00 \mathrm{FT} * \mathrm{FT} \cdot \mathrm{FIL}$

$R^{2}=0.98$

(D) TDM (min) $=16,78 \mathrm{FT}-804,20 \mathrm{FIL}+2028,70 \mathrm{FT} * \mathrm{FL}-1261,24 \mathrm{FT} * \mathrm{FT} * \mathrm{FIL}$

$R^{2}=0,89$

\section{FIGURA 3 - GRÁFICO DE SUPERFÍCIE DE RESPOSTA PARA A VARIAÇÃO DE ABSORÇÃO DE ÁGUA (\%), ESTABILIDADE (EST) (MIN), VARIAÇÃO DE ÍNDICE DE TOLERÂNCIA À MISTURA E TEMPO DE DESENVOLVIMENTO DA MASSA (MIN) DAS FARINHAS}

A adição de FIL reduziu significativamente a estabilidade e o tempo de desenvolvimento da massa, aumentando o índice de tolerância à mistura $(p<0,05)$. 0 modelo cúbico especial foi o que melhor explicou o efeito das farinhas mistas nesses fatores, aproximadamente $96 \%$, 88\% e $98 \%$ das variações ocorridas, respectivamente (Figuras 3B, 3C e 3D). Esse comportamento pode ser atribuído à diferença granulométrica da FIL (maior que na farinha de trigo) e à presença das fibras alimentares, que interferem na rede de glúten, impedindo a formação de rede proteica coesa e estável, causando ruptura da massa e redução de sua resistência ao amassamento em decorrência da interferência dos componentes da farinha de linhaça nas ligações cruzadas entre as gliadinas e gluteninas. As ligações de hidrogênio e de enxofre assumem grande importância na formação do glúten, na elasticidade, na extensibilidade, na impermeabilidade ao gás e no poder de absorção de água pela massa (INDRANI e RAO, 2007). A diminuição da resistência da massa ao amassamento foi comprovada pela perda da consistência ótima das massas produzidas com as farinhas mistas durante o processo. Lima (2007) observou comportamento semelhante em massas contendo farinha de linhaça nas concentrações de $4 \%, 7 \%$ e $10 \%$, quando comparadas ao controle contendo $100 \%$ de farinha de trigo. Sudha, Vetrimani e Leelavathi (2007) ao avaliarem a influência da adição de farinha de aveia e cevada nas características reológicas da massa de farinha de trigo obtiveram 
resultado similar. Gandra et al. (2008) observaram enfraquecimento da massa, registrando aumento nos valores do índice de tolerância à mistura (ITM) ao adicionarem farelo de trigo à farinha de trigo para elaboração de pães de forma.

\subsubsection{Propriedades extensíveis}

As Figuras 4A e 4B apresentam a equação de regressão, o coeficiente de determinação e a representação gráfica dos resultados de Rmax (UE) e $E(\mathrm{~mm})$ das farinhas mistas. O modelo quadrático para Rmax (UE) e cúbico especial para e $\mathrm{E}(\mathrm{mm})$ foram aqueles que melhor explicaram os efeitos das farinhas mistas de trigo e linhaça nas propriedades extensíveis da massa, demonstrando que $92,25 \%$ e $99,74 \%$ da variação ocorrida foram explicadas pela regressão.

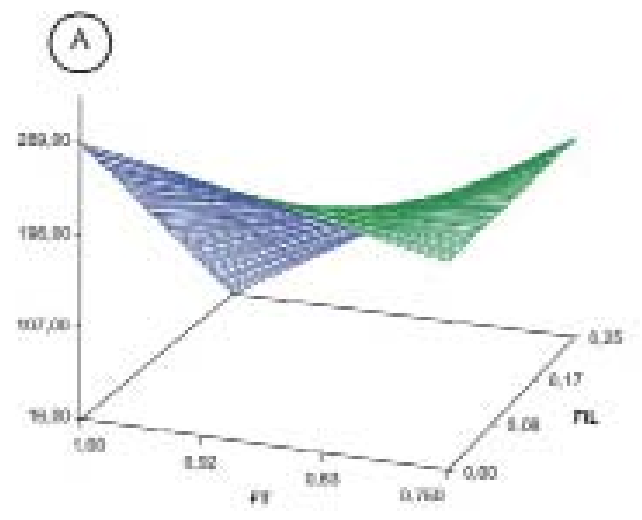

$R \max \left(\right.$ UE) $=289,31 \mathrm{FT}+3362,35 \mathrm{FIL}-4455,67 \mathrm{FT}{ }^{*} \mathrm{FIL}$

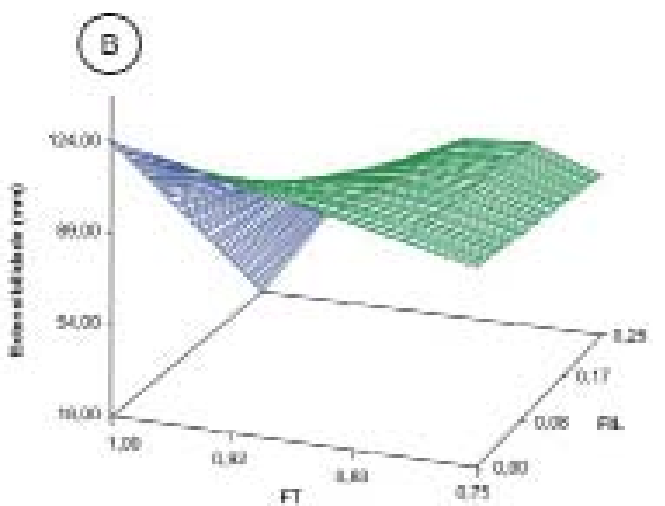

$R^{2}=0,82$

$E(m m)=124,18 \mathrm{FT}-5743,77 \mathrm{FIL}+14456,00 \mathrm{FT}{ }^{*} \mathrm{FIL}-9135,31 \mathrm{FT}{ }^{*} \mathrm{FT} \cdot \mathrm{FIL} \quad R^{2}=0,98$

\section{FIGURA 4 - GRÁFICO DE SUPERFÍCIE DE RESPOSTA PARA A VARIAÇÃO DE RESISTÊNCIA MÁXIMA À EXTENSÃO (UE) (MM) E EXTENSIBILIDADE (MM) DAS FARINHAS MISTAS DE TRIGO E LINHAÇA}

Conforme antecipado pelos resultados de farinografia, a adição de farinha de linhaça resultou em enfraquecimento do glúten e a massa não conservou sua extensibilidade e elasticidade, o que pode ser atribuído ao aumento de fibra insolúvel na mistura. Segundo Courtin, Roelantes e Delcour (1999) e Goesaert et al. (2005), a presença dessas fibras na massa reduz sua extensibilidade e aumenta sua resistência máxima à extensão.

O glúten representa a estrutura da massa de farinha de trigo e é responsável pelas características de extensibilidade e elasticidade (ou resistência à extensão) e no processo de panificação permite a retenção de gases e formação da estrutura do produto final. Wang, Rosell e Barber (2002) comentaram que as fibras interagem com as proteínas, agindo como pontos de fraqueza ou "stress", facilitando a ruptura física da matriz do glúten e, consequentemente, prejudicando a expansão da massa. Oliveira, Pirozi e Borges (2007) também observaram perdas nessas propriedades ao avaliarem farinhas mistas de trigo e linhaça nas proporções de 95:05, 90:10 e 85:15. A adição de farinha de linhaça prejudicou a qualidade tecnológica da massa pela redução de glúten, demonstrando que as diferentes misturas não apresentaram as características ideais para a produção de pão. Por outro lado, foi observado incremento na Rmax com o aumento crescente de farinha de linhaça nas misturas, o que pode ser atribuído à maior incorporação de lipídios polares na massa.

Asformulações contendo farinhaintegral de linhaçaapresentaram resultados extensográficos de massa muito rígida e curta, com redução de $\mathrm{E}$ e aumento da Rmax, demonstrando maior tendência ao encolhimento. A presença de glúten excessivamente elástico previne a expansão da massa na 
fermentação e forneamento, dando origem a pães pesados e com menor volume.

As massas obtidas a partir das farinhas mistas apresentaram consistência pegajosa, evidenciando quebra da estrutura do glúten e liberação de água. Essa característica foi mais acentuada nas formulações contendo $20 \%$ e $25 \%$ de farinha integral de linhaça e não permitiu o boleamento e a moldagem no extensógrafo. Assim, essa etapa foi realizada manualmente para todas as formulações.

Em concordância com os parâmetros farinográficos, as farinhas mistas utilizadas neste trabalho apresentaram características extensográficas impróprias à fabricação de pães.

\subsubsection{Número de Queda}

Todas as farinhas apresentaram número de queda superiores a 350 segundos, sendo consideradas de baixa atividade enzimática. O número de queda ideal para produção de pães varia de 200 a 250 segundos (PYLER, 1988; BRASIL, 2001). Esses resultados estão relacionados ao volume e textura final dos pães, pois farinhas com alta atividade enzimática geram pães pesados, com baixo volume e miolo pegajoso. As farinhas com baixa atividade enzimática geram pães com volume reduzido e miolo seco. Para as farinhas mistas estudadas, conforme sugerem Gutkoski e Jacobsen Neto (2002) e Goesaert et al. (2005), o desejável seria a suplementação enzimática ( $\alpha$ e $\beta$ amilase), visando melhorar a qualidade final do produto.

\section{CONCLUSÃO}

Ao ser incorporada à farinha de trigo, a farinha integral de linhaça afetou a distribuição granulométrica, produzindo farinhas mistas com granulometria mais grosseira e de cor mais escura, devido principalmente à presença de pericarpo da linhaça. Embora tenha favorecido as características de composição, como maior percentual de lipídios, fibra bruta, cinzas e proteínas, houve diminuição de qualidade tecnológica das farinhas mistas conforme o aumento dos níveis de substituição de farinha de trigo pela farinha integral de linhaça na mistura. Esse comportamento foi observado pela redução de extensibilidade, estabilidade e tempo de desenvolvimento da massa e pelo aumento do índice de tolerância à mistura e da tendência ao encolhimento. $O$ aumento do nível de substituição de farinha de trigo pela farinha integral de linhaça promoveu interferência negativa, principalmente das fibras nas propriedades tecnológicas da massa. Sugere-se que o uso de determinados aditivos e/ou de adequações no processamento poderá promover o desenvolvimento de características desejáveis à produção de pães.

\section{ABSTRACT \\ PHYSICOCHEMICAL AND RHEOLOGICAL CHARACTERIZATION OF MIXED WHEAT AND FLAXSEED FLOUR}

The objective of this work was to determine the effect of mixing flaxseed flour and wheat flour in the physicochemical and rheological properties, considering its use in baking products. Flour blends were prepared with the partial replacement of wheat flour for flaxseed flour as follows 100:00 95:5, 90:10, 85:15, 80:20 and 75:25. The flaxseed flour affected particle size distribution, producing composite flours that were coarser and darker in color, mainly due to the presence of flaxseed husk. Although increased the content of fat, crude fiber, ash and protein, the flaxseed flour decreased flour technological quality with its increasing replacement levels of wheat flour. This behavior was mainly expressed by decreasing in the extensibility, dough stability and dough development time and increase in the tolerance index. This negative effect was mainly due to the presence of fiber, which decreased the gluten technological properties. This problem could be solved using additives and/or making adjustments in the manufacturing process, in order to promote the development of desirable characteristics for bread production.

KEY-WORDS: WHEAT FLOUR; FLAXSEED FLOUR; COMPOSITE FLOUR; PHYSICOCHEMICAL CHARACTERISTICS; RHEOLOGICAL CHARACTERISTICS. 


\section{REFERÊNCIAS}

1 ANVISA. Agência Nacional de Vigilância Sanitária. Portaria n. 354, de 18 de julho de 1996. Norma técnica referente à farinha de trigo. Disponível em: <http://www.anvisa.gov.br>. Acesso em: 20 de setembro de 2011.

2 ANVISA. Agência Nacional de Vigilância Sanitária. Resolução n.383 de 05 de agosto de 1999. Regulamento técnico que aprova o uso de aditivos alimentares, estabelecendo suas funções e seus limites máximos para a categoria de alimentos 7, produtos de panificação e biscoitos. Diário Oficial [da] República Federativa do Brasil, Brasília-DF, 09 agosto de 1999.

3 AACC. American Association of Cereal Chemists. Approved methods of AACC. $9^{\text {th }}$ ed. Saint Paul, 1995. v. 2.

4 AOAC. Association of Official Agricultural Chemists. Official methods of analysis of the AOAC International. $16^{\text {th }}$ ed. Washington, 1995. v.2.

5 AOAC. Association of Official Agricultural Chemists. Official methods of analysis of the AOAC International. $16^{\text {th }}$ ed. Virginia, 1996. v.2.

6 BASMAN, A.; KOKSEL, H. Properties and composition of Turkish flan bread (Bazlana) supplemented with barley flour and wheat bran. Cereal Chemistry, v.76, n.4, p.506-511, Jul.-Aug. 1999.

7 BOMBO, A.J. Obtenção e caracterização nutricional de snacks de milho (Zea mays L.) e linhaça (Linum usitatissimum L.). 2006. 96 p. Dissertação (Mestrado em Saúde Pública), Universidade de São Paulo,

Faculdade de Saúde Pública, São Paulo, 2006.

8 BORGES, J.T.S.; ASCHERI; J.L.R.; ASCHERI, D.R.; NASCIMENTO, R.E.; FREITAS, A.S. Propriedades de cozimento e caracterização físico-química de macarrão pré-cozido à base de farinha integral de quinoa (Chenopodium quinoa, Wild) e de farinha de arroz (Oryza sativa, L) polido por extrusão termoplástica. Boletim do CEPPA, v.21, n.2, p.303-322, jul./ dez. 2003.

9 BRASIL. Ministério da Agricultura, Pecuária e Abastecimento. Instrução Normativa n.7, 15 de agosto de 2001. Regulamento técnico de identidade de qualidade do trigo. Diário Oficial [da] República Federativa do Brasil, 21 de agosto de 2001, Seção I, p.33-35.

10 BRASIL. Ministério da Agricultura, Pecuária e Abastaecimento. Instrução Normativa n.8, 02 de junho de 2005. Regulamento técnico de identidade e de qualidade da farinha de trigo. Diário Oficial [da] República Federativa do Brasil, Seção 1, n.105, 3 de junho de 2005.

11 CONFORTI, F.D.; DAVIS, S.F. The effect of soya flour and flaxseed as a partial replacement for bread flour in yeast bread. International Journal of Food Science and Technology, v.41, suppl.2, p.95-101, Dec. 2006.

12 COSKUNER, Y.; KARABABA, E. Some physical properties of flaxseed. Journal of Food Engineering, v.78, n.3, p.10671073, Feb. 2007.

13 COURTIN, C.M.; ROELANTS, A.; DELCOUR, J.A. Fractionation-reconstitution experiments provide insight into the role of endoxylanases in bread-making. Journal of Agricultural and Food Chemistry, v.47, n.5, p.1870-1877, Apr. 1999.

14 FELÍCIO, J.C.; CAMARGO, C.E.O.; GERMANI, R.; GALLO, P.B.; PEREIRA, J.C.V.N.A.; BORTOLETTO, N.; PETTINELLI, A.J. Influência do ambiente no rendimento e na qualidade de grãos de genótipos de trigo com irrigação por aspersão no estado de São Paulo. Bragantia, v.60, n.2, p.111-120, 2001.

15 FINNIE, S.M.; JEANNOTTE, R.; MORRIS, C.F.; FAUBION, J.M. Variation in polar lipid composition among near-isogenic wheat lines possessing different puroindoline haplotypes. Journal of Cereal Science, v.51, n.1, p.66-72, 2010.

16 FONSECA FILHO, A.A.; ARAÚJO, W.M.C.; FALCIROLLI, D.M.C.; PILLA, N.; MARQUES, A.O. Avaliação da qualidade tecnológica de pães enriquecidos com farelo de trigo. Alimentos e Nutrição, v.8, n.1, p.17-25, 1997.

17 FREITAS, D.G.C; MORETTI, R.H. Barra de cereais de elevado teor protéico e vitamínico: estabilidade enzimática e das vitaminas C e E durante o armazenamento. Archivos Latinosamericanos de Nutrición, v.56, n.3, set. 2006.

18 GANDRA, K.M.; DEL BIANCHI, M.; GODOY, V.P.; QUEIROZ, F.P.C.; STEEL, C.J. Aplicação de lipase e monoglicerídeo em pão de forma enriquecido com fibras. Ciência e Tecnologia de Alimentos, v.28, n.1, p.182-192, jan.-mar. 2008.

19 GIMÉNEZ, A.; VARELA, P.; SALVADOR, A.; ARES, G.; FISZMAN, S.; GARITTA, L. Shelf life estimation of brown pan bread: a consumer approach. Food Quality and Preference, v.18, n.2, p.196-204, Mar. 2007.

20 GOESAERT, H.; BRIJS, K.; VERAVERBEKE, W.S.; COURTIN, C.M.; GEBREUS, K.; DELCOUR, J.A. Wheat flour constituents: how they impact bread quality, and how to impact their functionality. Trends in Food Science and Technology, v.16, n.1-3, p.12-30, Jan.-Mar. 2005.

21 GUARIENTI, E.M. Qualidade industrial de trigo. Passo Fundo: Embrapa-CNPT, 1996. 36 p. (Documentos, 27). 
22 GUNNING, P.A.; MACKIE, A.R.; WILDE, P.J.; MORRIS, V.J. "In situ" observation of the surfactant-induced displacement of protein from a graphite surface by atomic force microscopy. Langmuir, v.15, n.13, p.4636-4640, May 1999.

23 GUTKOSKI, L.C.; NODARI, M.L.; JACOBSEN NETO, R. Avaliação de farinhas e trigos cultivados no Rio Grande do Sul na produção de biscoitos. Ciência e Tecnologia de Alimentos, v.23, p.91-97, dez. 2003.

24 GUTKOSKI, L.C.; DURIGON, A.; MAZZUTTI, S.; SILVA, A.C.T.; ELIAS, M.C. Efeito do período de maturação de grãos nas propriedades físicas e reológicas de trigo. Ciência e Tecnologia de Alimentos, v.28, n.4, p.888-894, out.-dez. 2008.

25 GUTKOSKI, L.C.; JACOBSEN NETO, R. Procedimento para teste laboratorial de panificação-pão tipo forma. Ciência Rural, v.32, n.5, p.873-879, set.-out. 2002.

26 GUTKOSKI, L.C.; PEDÓ, I. Aveia: composição química, valor nutricional e processamento. São Paulo: Varela, 2000.96 p.

27 HAROS, M.; ROSELL, C.M.; BENEDITO, C. Effect of different carbohydrases on fresh bread texture and bread staling. European Food Research and Technology, v.215, n.5, p.425-430, Nov. 2002.

28 HASAN, F.; SHAH, A.A.; HAMEED, A. Industrial applications of microbial lipases. Enzyme and Microbial Technology, v.39, n.2, p.235-251, Jun. 2006

$29 \mathrm{HU}, \mathrm{G}$; ; HUANG, S.; CAO, S.; MA, Z. Effect of enrichment with hemicellulose from rice bran on chemical and functional properties of Bread. Food Chemistry, v.115, n.3, p.839-842, Aug. 2009.

30 HUNTERLAB. User's manual with universal software versions 3.5. Reston, 1998.

31 HUSSAIN, S.; ANJUM, F.M.; BUTT, M.S.; KHAN, M.I.; ASGHAR, A. Physical and sensory attributes of flaxseed flour supplemented cookies. Turkish Journal of Biology, v.30, n.2, p.87-92, May 2006.

32 INDRANI, D.; RAO, G.V. Rheological characteristics of wheat flour dough as influenced by ingredients of Parotta. Journal of Food Engineering, v.79, n.1, p.100-105, Mar. 2007.

33 JUSTO, M.B.; ALFARO, A.D.C.; AGUILAR, E.C.; WROBEL, K.; WROBEL, K.; GUZMÁN, G.A.; SIERRA, Z.G.; ZANELLA, V.M. Desarrollo de pan integral con soya, chía, linaza y ácido fólico como alimento funcional para la mujer. A r c $\mathbf{h}$ i v o s LatinoAmericanos de Nutrición, v.57, n.1, p.78-84, mar. 2007.

34 KELLER, R.C.; ORSEL, R.; HAMER, R.J. Competitive absorption behavior of wheat flour components and emulsifiers at air-water interface. Journal of Cereal Science, v.25, n.2, p.175-183, Mar. 1997.

35 KOCA, A.F.; ANIL, M. Effect of flaxseed and wheat flour blends on dough rheology and bread quality. Journal of the Science of Food and Agriculture v.87, n.6, p.1172-1175, Apr. 2007.

36 LEÓN, A.E.; DURÁN, E.; BARBER, C.B. Utilization of enzyme mixtures to retard bread crumb firming. Journal of Agricultural and Food Chemistry, v.50, n.6, p.1416-1419, Febr. 2002.

37 LI, W.; DOBRASZCZYK, B.J.; WILDE, P.J. Surface properties and locations of gluten proteins and lipids revealed using confocal scanning laser microscopy in bread dough. Journal of Cereal Science, v.39, n.3, p.403-411, May 2004.

38 LI-CHAN, E.C.Y.; MA, C.-Y. Thermal analysis of flaxseed (Linum|usitatissimun) proteins by differential scanning calorimetry. Food Chemistry, v.77, n.4, p.495-502, Jun. 2002

39 LIMA, C.C. Aplicação das farinhas de linhaça (Linum usitatissimum L.) e maracujá (Passiflora edulis Sims f. flavicarpa Deg.) no processamento de pães com propriedades funcionais. 2007. 148 p. Dissertação (Mestrado em Ciência e Tecnologia de Alimentos), Universidade Federal do Ceará, Fortaleza, 2007.

40 LOPES, A.S.; ORMENESE, R.C.S.C.; MONTENEGRO, F.M.; FERREIRA JÚNIOR, P.G. Influência do uso simultâneo de ácido ascórbico e azodicarbonamida na qualidade do pão francês. Ciência e Tecnologia de Alimentos, v.27, n.2, p.307312, abr.-jun. 2007.

41 MACIEL, L.M.B.; PONTES, D.F.; RODRIGUES, M.C.P. Efeito da adição de farinha de linhaça no processamento de biscoito tipo cracker. Alimentos e Nutrição, v.19, n.4, p.385-392, out.-dez. 2008.

42 MCCANN, T.H.; SMALL, D.M.; BATEY, I.L.; WRIGLEY, C.W.; DAY, L. Protein-lipid interactions in gluten elucidated using acetic-acid fractionation. Food Chemistry, v.115, n.1, p.105-112, Jul. 2009.

43 MANDARINO, J.M.G.; ROESSING, A.C.; BENASSI, V.T. Óleo: alimentos funcionais. Londrina: Embrapa Soja, 2005.91 p.

44 MEAGHER, L.P.; BEECHER, G.R. Assessment of data on the lignan content of foods. Journal of Food Composition and Analysis, v.13, n.6, p.935-947, Dec. 2000.

45 MORAES, E.A.; DANTAS, M.I.S.; MORAIS, D.C.; SILVA, C.O.; CASTRO, F.A.F.; MARTINO, H.S.D.; RIBEIRO, S.M.R. Sensory evaluation and nutritional value of cakes prepared with whole flaxseed flour. Ciência e Tecnologia de Alimentos, 
v.30, n.4, p.974-979, out.-dez 2010.

46 MOURA, N.C. Características físico-químicas, nutricionais e sensoriais de pão de forma com adição de grãos de linhaça (Linum usitatissimum). 2008. 94 p. Dissertação (Mestrado em Ciência e Tecnologia de Alimentos), Universidade de São Paulo, Escola Superior de Agricultura "Luiz de Queiroz", São Paulo, 2008.

47 NÉRON, S.; EL AMRANI, F.; POTUS, J.; NICOLAS, J. Separation and quantification by high-performance liquid chromatography with light scattering detection of the main wheat flour phospholipds during dough mixing in the presence of phospholipase. Journal of Chromatography A, v.1047, n.1, p.77-83, Aug. 2004.

48 OLIVEIRA, T.M.; PIROZI, M.R.; BORGES, J.T.S. Elaboração de pão de sal utilizando farinha mista de trigo e linhaça. Alimentos e Nutrição, v.18, n.2, p. 141-150, abr.-jun. 2007.

49 OOMAH, B.D. Flaxseed as a functional food source. Journal of the Science of Food and Agriculture, v.81, n.9, p.889894, Jul. 2001

50 OOMAH, B.D.; MAZZA, G. Flaxseed proteins: a review. Food Chemistry, v.48, n.2, p.109-114, 1993.

51 OOMAH, B.D.; MAZZA, G.; PRZYBYLSKI, R. Comparison of flaxseed meal lipids extracted with different solvents. LWTFood Science and Technology, v.29, n.7, p. 654-658, Nov. 1996.

52 PEREZ, P.M.P.; GERMANI, R. Farinha mista de trigo e berinjela: características físicas e químicas. Boletim do CEPPA, v.22, n.1, p.15-24, jan.-jun. 2004.

53 POUTANEN, K. Enzymes: an important tool in the improvement of the quality of cereal foods. Trends in Food Science \& Technology, v.8, n.9, p.300-306, Sep.1997.

54 PYLER, E.J. Baking: science \& tecnology. $3^{\text {rd }}$ ed. Kansas: Sosland Publ., 1988. v.2.

55 QUEJI, M.F.D.; SCHEMIN, M.H.; TRINDADE, J.L.F. Propriedades reológicas da massa de farinha de trigo adicionada de alfa-amilase. UEPG, Ciências Exatas e da Terra, Ciências Agrárias e Engenharias, v.12, n.2, p.21-29, ago. 2006.

56 RAMCHARITAR, A.; BADRIE, N.; MATTFELDT-BEMAN, M.; MATSUO, H.; RIDLEY, C. Consumer acceptability of muffins with flaxseed (Linum usitatissimum). Journal of Food Science, v.70, n.7, p.504-507, Sep. 2005.

57 ROSELL, C.M.; ROJAS, J.A.; BARBER, C.B. Influence of hydrocolloids on dough rheology and bread quality. Food Hydrocolloids, v.15, n.1, p.75-81, Jan. 2001.

58 SAS INSTITUTE. The SAS System for Windows (Statistical Analysis System), release 6.12 software. Cary, 1996.

59 SEYER, M.E.; GELINAS, P. Bran characteristics and wheat performance in whole wheat bread. International Journal of Food Science and Technology, v.44, n.4, p.688-693, Apr. 2009.

60 SHEARER, A.E.H.; DAVIES, C.G.A. Physicochemıcal propertıes of freshly baked and stored whole-wheat muffıns with and without flaxseed meal. Journal of Food Quality, v.28, n.2, p.137-153, Apr. 2005.

61 SUDHA, M.L.; VETRIMANI, R.; LEELAVATHI, K. Influence of fibre from different cereals on the rheological characteristics of wheat flour dough and on biscuit quality. Food Chemistry, v.100, n.4, p.1365-1370, 2007.

62 TEDRUS, G.A.S.; ORMENESE, R.C.S.; SPERANZA, S.M.; CHANG, Y.K.; BUSTOS, F.M. Estudo da adição de vital glúten a farinha de arroz, farinha de aveia e amido de trigo na qualidade dos pães. Ciência e Tecnologia de Alimentos, v.21, n.1, p.20-25, 2001.

63 VAN DER MAAREL, M.J.E.C.; VAN DER VEEN, B.; UITDEHAAG, J.C.M.; HANS LEEMHUIS, H.; DIJKHUIZEN, L. Properties and applications of starch-converting enzymes of the alpha-amylase family. Journal of Biotechnology, v.94, n.2, p.137-155, Mar. 2002.

64 WANG, J.; ROSELL, C.M.; BARBER, C.B. Effect of the addition of different fibres on wheat dough performance and bread quality. Food Chemistry, v.79, n.2, p.221-226, Nov. 2002.

65 WU, W.; HUFF, H.E.; HSIEHI, F. Processing and properties of extruded flaxseed-corn puff. Journal of Food Processing and Preservation, v.31, n.2, p.211-226, Apr. 2007.

66 ZHANG, W.; XU, S.; WANG, Z.; YANG, R.; LU, R. Demucilaging and dehulling flaxseed with a wet process. LWT-Food Science and Technology, v.42, n.6, p.1193-1198, Jul. 2009.

\section{AGRADECIMENTOS}

À Coordenação de Aperfeiçoamento de Pessoal de Nível Superior (CAPES) pela bolsa concedida e ao Departamento de Tecnologia de Alimentos da Universidade Federal de Viçosa pela realização do experimento. 